\title{
Correction to: Microbial Porous Carbon by Low-Alkali Activation for Flexible Supercapacitors
}

\author{
Diwen Zhu ${ }^{1}$. Junwen Hou ${ }^{1} \cdot$ Lijin Zhang $^{1} \cdot$ Yanfeng Gao ${ }^{1}$ Bingru Dai ${ }^{1} \cdot$ Yue Lian ${ }^{2} \cdot$ Haishui Yan ${ }^{1} \cdot$ Huaihao Zhang ${ }^{2}$
}

Published online: 6 October 2021

(c) The Minerals, Metals \& Materials Society 2021

Correction to: Journal of Electronic Materials.

https://doi.org/10.1007/s11664-021-09213-y

The Acknowledgments in the original online version of this article was corrected as follows:

This work was financially supported by the Undergraduate Innovation \& Entrepreneurship Training Program (202013987016Y, 202013987003Y). The related measurement and analysis instrument for this work was supported by the Testing Center of Yangzhou University.

Publisher's Note Springer Nature remains neutral with regard to jurisdictional claims in published maps and institutional affiliations.

The original article can be found online at https://doi.org/10.1007/ s11664-021-09213-y.

Huaihao Zhang

huaihaozhang@163.com

1 Chemical and Medicine Department, Guangling College, Yangzhou University, Yangzhou 225009, People's Republic of China

2 School of Chemistry and Chemical Engineering, Yangzhou University, Yangzhou 225002, People's Republic of China 